unhappy about those on electricity and magnetism. His complaint is that he failed to discover a unique or different way of presenting the subject from that usually followed. The lengthy mathematical discussions needed to deal with electromagnetic phenomena may indeed worry the student as he looks through Volume 2 and considers that he must absorb the contents together with many other topics during his all-too-short academic course.

Twelve lectures at the end of the second year were devoted to quantum mechanics, but these were later supplemented by seven additional lectures in May 1964 . By reprinting Chapters 37 and 38 of Volume 1 as the first two chapters of the third volume and adding the edited version of the quantum mechanics lectures, Volume 3 is a self-contained unit relatively independent of the other two volumes. Following the initial statement of quantum behaviour, probability amplitudes, spin and one-state systems are discussed. The ammonia maser is used to introduce the consideration of two-state systems, and then the propagation of electrons in crystals, semiconductors, symmetry and conservation laws, and the quantum mechanics of angular momentum are dealt with. The volume concludes its introduction to quantum mechanics by a treatment of the Schrödinger wave equation and its solution in the case of the hydrogen atom.

Feynman was well aware that the best teaching can be done only when there is a direct individual relationship betwcen student and teacher. His lectures suffered because there was little or no feedback from the audience to the lecturer, but he puts forward the excuse that when to-day there are so many students to teach there must be some substitute for the ideal, and he expresses the hope that his lectures and subsequent text will meet the present need. Lecturers in universities and technical colleges will be grateful for the experiment he made, and for the record that they can study in detail. The Lectures provide a first-rate background for the further study of physics, and an excellont guide to the preparation of lectures which will capture and maintain the interest of students with the obvious success and enjoyment that Feynman's achieved.

S. Weintroub forward but somewhat old-fashioned way, based on the Carnot eycle. Chapter 3 is entitled "The Solution of Ions", but includes discussions of polar and non-polar bonding, and detailed accounts of different types of molecular interaction, of lattice energies, and of the theory of liquid dielectrics, all with a good deal of algebra. These three chapters occupy nearly one-quarter of the book, and contain little which could not be found in general treatises on physical chemistry.

Chapters 4-9 deal with the usual topies of classical electrochemistry, such as strong and weak electrolytes, ionic interaction, and the theory and applications of conductance and e.m.f. measurements. The exposition and choice of material are excellent, and (as throughout tho book) there are copious references to general articles and original papers. A few sections have not been brought fully up to date: thus three pages are devoted to the quinhydrone and antimony electrodes but only one to the glass electrode; the section on dissociation of acids in deuterium oxide gives no references later than 1938; and the kinetic salt effect is not related to transition state theory.

The final three chapters, comprising more than one-third of the book, represent its most valuable contribution. Topics treated include potential differences at phase boundaries, over-potential, electrode kinetics, corrosion and passivity, and polarography and other electrochemical analytical techniques. These chapters are truly up to date, and the author provides a welcome guide to the confusing variety of facts and theories in controversial fields such as electrode polarization. There is much interesting information about practical applications in fiolds such as electrometallurgy, fuel cells and ion-exchange resins, and attention is drawn to many important theoretical and practical problems which remain unsolved.

To sum up, this book contains much of value to research workers in the field of electrolytes and to advanced students of physical chemistry, though it could have been made more digestible (and cheaper) by abbreviating the earlier sections. It should certainly be in any well-stocked chemical library.

R. P. BELL

\section{MODERN ELECTROCHEMISTRY}

\section{Treatise on Electrochemistry}

By G. Kortüm. Second, completely revised Englih edition. Pp. xxii +637 . (Ansterdam, London and New York: Elsevier Publishing Company, 1965.) $170 s$.

THE previous English edition of Prof. Kortüm's Treatise on Electrochemistry (1951) was a two-volume work, based on the first German edition (1948), but with a great deal of additional material added by J. O'M. Bockris, including chapters on experimental techniques in electrochemistry, numerical examples for tho student and tables of electrochemical data. The volume under review is a new translation of the third German edition (1962), with some modifications to bring it up to date. It does not include the additional material of the first English edition, and thereby regains the unity of the German text. The translation is adequate but inelegant, and the literal translation of German words often produces terms which will be unfamiliar to the English-speaking reader, for examplo 'fortility' and 'influence constant' (in electrostatics), and 'first and last heats of solution'. Occasionally this leads to mis-translations such as 'prüfen' as 'provo' and 'evontuell' as 'eventually'.

The first three chapters are introductory in character, and could well have been shortened considerably, or even omitted altogether, in a book of this nature. Chapter 1 contains much elementary electricity and magnetism, such as Ohm's law, Gauss's theorem, the Poisson equation, otc., all worked through in detail. Chapter 2 works through thermodynamies from seratch in a straight-

\section{HOT GLASS}

\section{Structural Transformations in Glasses at High Temper-} atures

Edited by N. A. Toropov and E. A. Porai-Koshits. Authorized translation from the Russian by E. B. Uvarov. (The Structure of Glass, Vol. 5.) Pp. ix +223 . (New York: Consultants Bureau, 1965.) 25 dollars.

Studies in the field of glass technology and the chemistry and physics of the silicates have been very active in the U.S.S.R. for some considerable time. In recent years four All-Union conferences on the glassy state have been held and the Consultants Bureau has made available translations of the proceedings of these conferences. This is a very useful service, particularly as some of the volumes have been published in translation almost simultaneously with their appearance in Russian.

Volume 3, which formed the proceedings of the fourth All-Union conference on the glassy state, was sub-titled "Catalysed Crystallisation of Glass". This showed that a very considerable effort $w$ as being placed in the U.S.S.R. on the development of the glass-ceramics, introduced in the late 1950 's as "pyrocerams" by Corning Glass Works. Structural Transformations in Glasses at High Temperatures, published only one year later, shows that this effort is not being relaxed at all. Although the title is different, with one exception the papers in the present volume are also concerned with nucleation and crystal growth, an understanding of which is a necessary background for the development of successful glass ceramies. 